\title{
Atomic Layer Deposition of Noble Metals - New Developments in Nanostructured Catalysts
}

\author{
Junling Lu, Yu Lei and Jeffrey W. Elam* \\ Argonne National Laboratory, Argonne, IL
}

USA

\section{Introduction}

This chapter will review recent progress in the use of atomic layer deposition (ALD) to prepare noble metal nanoparticle catalysts in which the nanoparticle size, composition, and local environment can be tailored on the atomic scale to tune the reactivity, selectivity, and thermal stability of the catalysts. ALD is a thin film growth technique that uses alternating cycles of self-limiting chemical reactions between gaseous precursors and a solid surface to deposit material in an atomic layer-by-layer fashion ${ }^{1}$. By combining ALD processes for metal oxides, noble metals, and other materials relevant to catalysis, it is possible to engineer nanostructured catalysts with unique properties by depositing a sequence of discrete layers or particles which each perform a specific function. Although the idea of using ALD to prepare catalysts is not new ${ }^{2}$, recent advances in ALD technology, coupled with innovative ideas for nanofabrication, have rekindled this field and now offer potential solutions to long-standing problems in catalyst synthesis.

We begin with a brief introduction to ALD. A broad variety of materials can be deposited by ALD using alternating exposures of two chemicals. For example, aluminum oxide $\left(\mathrm{Al}_{2} \mathrm{O}_{3}\right)$ ALD uses sequential exposures to trimethyl aluminum (TMA) and $\mathrm{H}_{2} \mathrm{O}$ as illustrated in Fig. $1^{3}$. In reaction $A$, the substrate to be coated is exposed to TMA vapor which reacts with surface hydroxyl groups $(\mathrm{OH})$ to form new $\mathrm{O}-\mathrm{Al}$ linkages and liberate methane $\left(\mathrm{CH}_{4}\right)$ into the gas phase. This reaction proceeds until all of the $\mathrm{OH}$ groups are consumed at which point the reaction terminates because the TMA is inert towards the methyl-terminated surface. In reaction $\mathrm{B}, \mathrm{H}_{2} \mathrm{O}$ vapor is introduced which reacts with the surface methyls producing $\mathrm{CH}_{4}$ gas and again forming new Al-O linkages. Reaction B stops when all of the methyl groups are gone because the $\mathrm{H}_{2} \mathrm{O}$ does not react with surface hydroxyls. The net result of one $\mathrm{A} / \mathrm{B}$ cycle is to deposit a monolayer of $\mathrm{Al}_{2} \mathrm{O}_{3}$ on the surface and to regenerate the original starting surface so that the process can be repeated.

ALD reactors typically incorporate a chamber heated to $\sim 100-400^{\circ} \mathrm{C}$ containing the substrate to be coated 4 . A constant stream of inert gas such as $\mathrm{N}_{2}$ flows through the chamber at a pressure of $\sim 0.1-10$ Torr. The precursor vapors are injected into the carrier gas using pulsed valves and transported to the substrate where they react, and any excess precursor and

${ }^{*}$ Corresponding Author 
byproduct gases are swept away. Desirable characteristics for ALD precursors include high volatility, good thermal stability at the ALD growth temperatures, and high reactivity with the other compound used for the film growth. A purge period is introduced between each precursor dose to prevent mixing of the chemicals which would cause non self-limited growth. Each ALD cycle can last seconds to hours depending on factors such as the reactivity of the precursors and the surface area and porosity of the substrate. ALD research and process development are greatly facilitated using in-situ measurements. For instance, an in-situ quartz crystal microbalance (QCM) with sub-monolayer sensitivity and $10-20 \mathrm{~Hz}$ update rate, is a valuable tool for monitoring film growth in real time, and can also provide details for understanding the ALD surface chemistry. Similarly, an in situ quadrupole mass spectrometer (QMS) installed in the reactor can help to understand the growth mechanism by identifying the gas phase products of the ALD surface reactions.

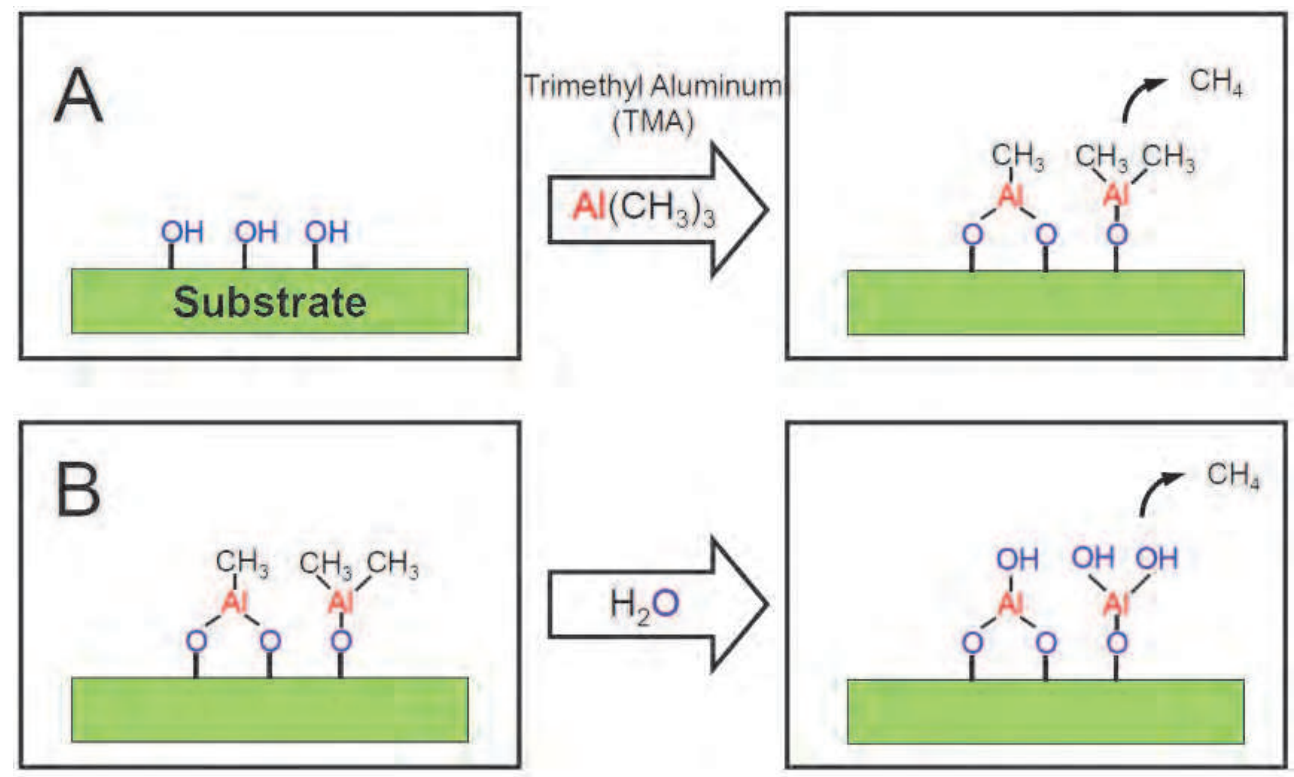

Fig. 1. Schematic illustration of surface chemistry for $\mathrm{Al}_{2} \mathrm{O}_{3} \mathrm{ALD}$.

One of the hallmarks of an ALD process is that the reactions saturate after a certain minimum exposure, after which additional precursor flux does not deposit more material. For instance, Fig. 2a shows that the $\mathrm{Al}_{2} \mathrm{O}_{3}$ ALD saturates at $1.2 \AA$ /cycle following a TMA exposure of $\sim 0.05$ Torr s. A natural consequence of this self-limiting behavior is that the film thickness increases by a fixed amount with each A/B cycle. This behavior is displayed in Fig. $2 \mathrm{~b}$ where the $\mathrm{ALD} \mathrm{Al}_{2} \mathrm{O}_{3}$ thickness was measured by ellipsometry over a wide range of $\mathrm{A} / \mathrm{B}$ cycles and the growth is exceptionally linear ${ }^{5}$. A second consequence of the selfterminating surface chemistry is that the precursor molecules can diffuse into narrow pores until they encounter an empty site, and in this way nanoporous materials can be coated with great uniformity. This capability is extremely useful for catalyst synthesis ${ }^{6}$. 
Figure $2 \mathrm{~b}$ demonstrates that the $\mathrm{Al}_{2} \mathrm{O}_{3}$ ALD growth rate does not change with the number of cycles, and in particular the earliest cycles deposit virtually the same amount of $\mathrm{Al}_{2} \mathrm{O}_{3}$ as the later cycles. This behavior is typical of most ALD metal oxides and results from the prompt nucleation or initiation of metal oxide ALD on most surfaces (due to the ubiquity of $\mathrm{OH}$ groups), and usually generates very uniform, continuous films. In contrast, the ALD of noble metals such as palladium often shows a long incubation period on oxide surfaces ${ }^{7}$. This nucleation delay stems from the difficulty in removing the ligands from the noble metal precursor bound to an oxide surface. This poor nucleation, coupled with the natural tendency for noble metal atoms to diffuse and agglomerate, results in the formation of discrete metal islands which grow with increasing numbers of ALD cycles until finally converging to form a continuous film. Although this tendency is undesirable for microelectronics applications, it is ideal for preparing catalytic nanoparticles which must be highly dispersed and of nanometer size. Smaller nanoparticles are typically more active on a per-atom basis because the surface area to volume ratio increases with decreasing thickness. Moreover, the lower radius of curvature for smaller nanoparticles produces a larger fraction of under-coordinated surface atoms, which often have the highest catalytic activity. For these reasons, the following sections will highlight efforts to control the nanoparticle size, and in particular to achieve ultra-small $(<1 \mathrm{~nm})$ noble metal nanoparticles.
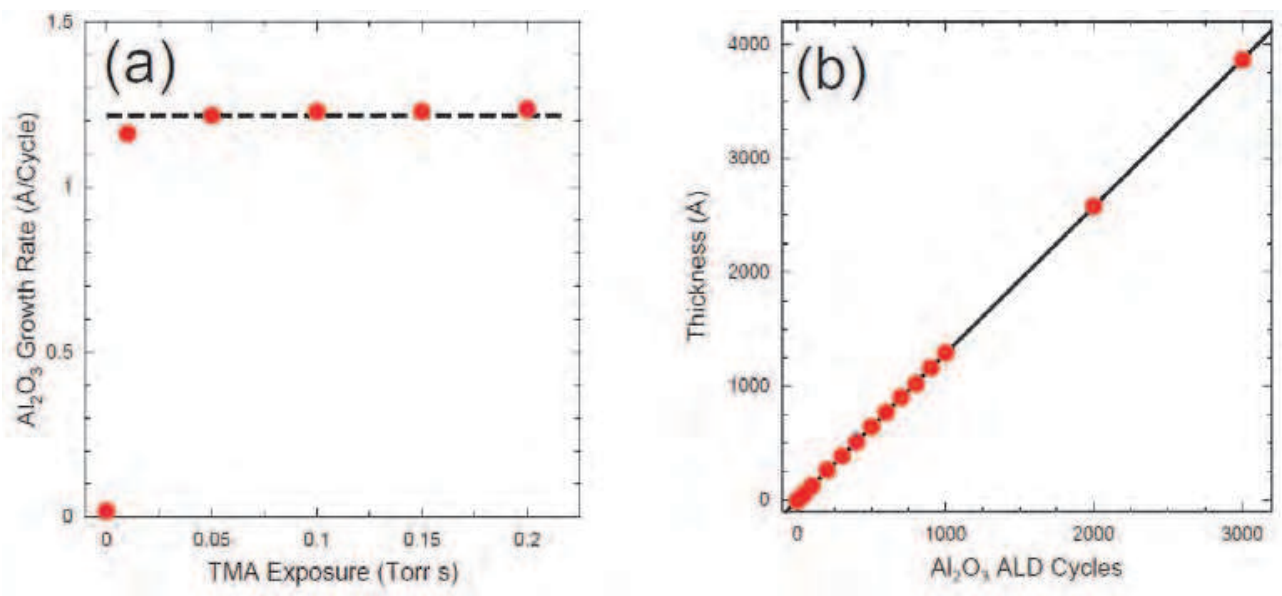

Fig. 2. (a) Saturation of $\mathrm{ALD} \mathrm{Al}_{2} \mathrm{O}_{3}$ growth rate versus TMA exposure; (b) Linear growth of ALD $\mathrm{Al}_{2} \mathrm{O}_{3}$ versus number of $\mathrm{Al}_{2} \mathrm{O}_{3}$ ALD cycles.

In addition to depositing simple binary compounds such as $\mathrm{Al}_{2} \mathrm{O}_{3}$ and elements such as $\mathrm{Pd}$, ALD can also synthesize ternary and more complex compounds such as $\mathrm{ZnAl}_{2} \mathrm{O}_{4}{ }^{8}$, as well as mixed metals such as Pt-Ir9. The ALD of mixed materials is accomplished by alternating between the binary reaction sequences of the individual components in the mixture, and the composition is controlled by adjusting the ratio of ALD cycles for the different components. The ability to control the composition of a metal oxide support layer allows properties such as the surface acidity to be adjusted in a manner analogous to 
the $\mathrm{Al} / \mathrm{Si}$ ratio in zeolites, and mixed-metal nanoparticles such as Pt-Ru often exhibit superior catalytic properties.

The capability to produce both thin, continuous layers as well as discrete nanoparticles makes it possible to engineer an "ideal catalyst" using a sequence of ALD processes as illustrated in Fig. 3. Starting from a substrate with the desired porosity, surface area, and nanostructure, the support layer is first applied by ALD in the form of a physically thin but chemically thick layer $(\sim 1 \mathrm{~nm})$. Next, catalytic nanoparticles are deposited by ALD on top of the support layer with the desired size, composition, dispersion, and nanostructure. A final ALD process can be used to stabilize the nanoparticles against sintering, or to modify their catalytic behavior. The following sections will provide examples for all of the steps in this synthesis scheme. In particular, we will describe ALD of the noble metals Pt, Pd, and Ir, and the mixed-noble metals Pt-Ir, Pt-Ru, and Pt-Pd. We will show the effects of different ALD support layers $\left(\mathrm{Al}_{2} \mathrm{O}_{3}, \mathrm{TiO}_{2}, \mathrm{ZrO}_{2}\right.$, and $\left.\mathrm{ZnO}\right)$ as well as the influence of ALD over-layers on the stability and reactivity of catalytic nanoparticles.

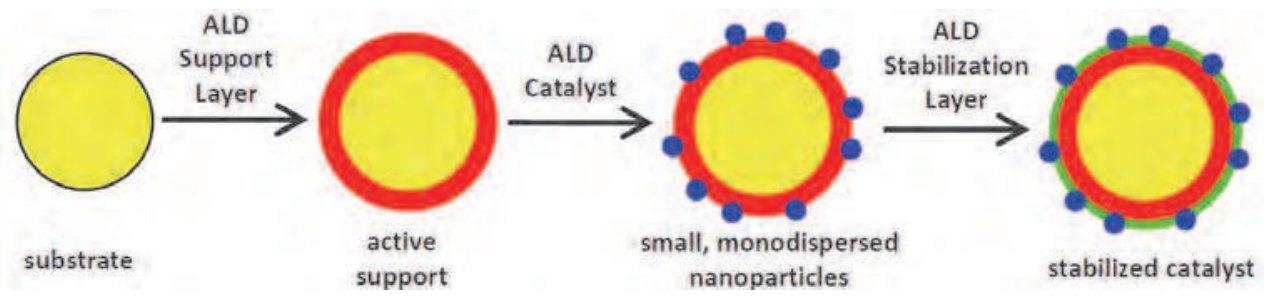

Fig. 3. Schematic illustration of catalyst synthesis by ALD.

\section{Palladium ALD}

Palladium (Pd) is a common metal for heterogeneous catalysis with applications in methanol partial oxidation and the water-gas shift reaction. Palladium ALD can be accomplished using $\mathrm{Pd}(\mathrm{II})$ hexafluoroacetylacetonate $\left(\mathrm{Pd}(\mathrm{hfac})_{2}\right)$ which has a relatively high vapor pressure compared to other $\beta$-diketonate derivatives of Pd. ${ }^{10}$ Senkevich et al. demonstrated Pd ALD at $80{ }^{\circ} \mathrm{C}$ on Ir metal surfaces, where atomic hydrogen, formed from the dissociation of $\mathrm{H}_{2}$ on the Ir surface, served as the reducing reagent. ${ }^{11}$ To increase the substrate generality, Ten Eyck et al. used a remote hydrogen plasma for Pd ALD on Ir, W, and Si surfaces. ${ }^{12}$ However, plasmas are not well suited to catalyst synthesis because they require line-of-site between the plasma and the substrate surface which is impractical for nanoporous catalyst templates. The lack of a suitable reducing reagent for Pd ALD on porous oxide surfaces has limited the development of ALD Pd catalysts.

This problem was solved by using formalin as the reducing reagent. ${ }^{7}$ Pd ALD was investigated using amorphous $\mathrm{ALD} \mathrm{Al}_{2} \mathrm{O}_{3}$ as the support material. The reaction mechanism during the first Pd ALD cycle was suggested to be:

$$
\begin{aligned}
& \mathrm{Al}-\mathrm{OH}^{*}+\mathrm{Pd}(\mathrm{hfac})_{2} \rightarrow \mathrm{Al}-\mathrm{O}-\mathrm{Pd}(\mathrm{hfac})^{*}+\text { hfacH } \\
& \mathrm{Al}-\mathrm{O}-\mathrm{Pd}(\mathrm{hfac})^{*}+\mathrm{HCOH} \rightarrow \mathrm{Al}-\mathrm{O}-\mathrm{Pd}-\mathrm{H}_{x}{ }^{*}+\mathrm{hfacH}+\mathrm{CO}+0.5(1-\mathrm{x}) \mathrm{H}_{2}
\end{aligned}
$$


Here hfacH represents hexafluoroacetylacetone, and the asterisks designate surface species. In this mechanism, the $\mathrm{Pd}(\mathrm{hfac})_{2}$ precursor first reacts with the surface hydroxyl and is then reduced by atomic hydrogen produced from $\mathrm{HCOH}$. The formation of $\mathrm{Pd}$ nanoparticles could occur during reaction 1, 2, or both. In situ quartz crystal microbalance $(\mathrm{QCM})$, measurements revealed a nucleation period of slower Pd growth on the $\mathrm{Al}_{2} \mathrm{O}_{3}$ surface before reaching a steady-state Pd growth rate of $0.2 \AA$ /cycle at $200{ }^{\circ} \mathrm{C}$. The Pd nucleation could be accelerated using larger initial $\mathrm{Pd}(\mathrm{hfac})_{2}$ and formalin exposures (Fig. 4). (Contrast the delayed $\mathrm{Pd}$ nucleation in Fig. 4 with the prompt $\mathrm{Al}_{2} \mathrm{O}_{3}$ nucleation in Fig. $2 \mathrm{~b})$. The slow nucleation period was believed to result from slower kinetics for hfac removal by $\mathrm{HCOH}$ on the oxide surface, or from surface poisoning by readsorption of the hfacH product on the $\mathrm{Al}_{2} \mathrm{O}_{3}$ surface. The later hypothesis was supported by X-ray photoelectron spectroscopy studies that identified residual fluorine on the surface of thin ALD Pd films. George et al. suggested $\mathrm{Pd}(\mathrm{hfac})_{2}$ adsorbs on hydroxylated $\mathrm{Al}_{2} \mathrm{O}_{3}$ surfaces primarily through dissociative adsorption based on only a slight loss of hydroxyl coverage during $\mathrm{Pd}(\mathrm{hfac})_{2}$ absorption as observed by in situ Fourier transform infrared (FTIR) spectroscopy. ${ }^{13}$ Surface poisoning by adsorbed hfacH was found to be much less pronounced on $\mathrm{TiO}_{2}$ and $\mathrm{ZnO}$ surfaces as evidenced by the much shorter nucleation delay of Pd ALD on these surfaces. ${ }^{14}$

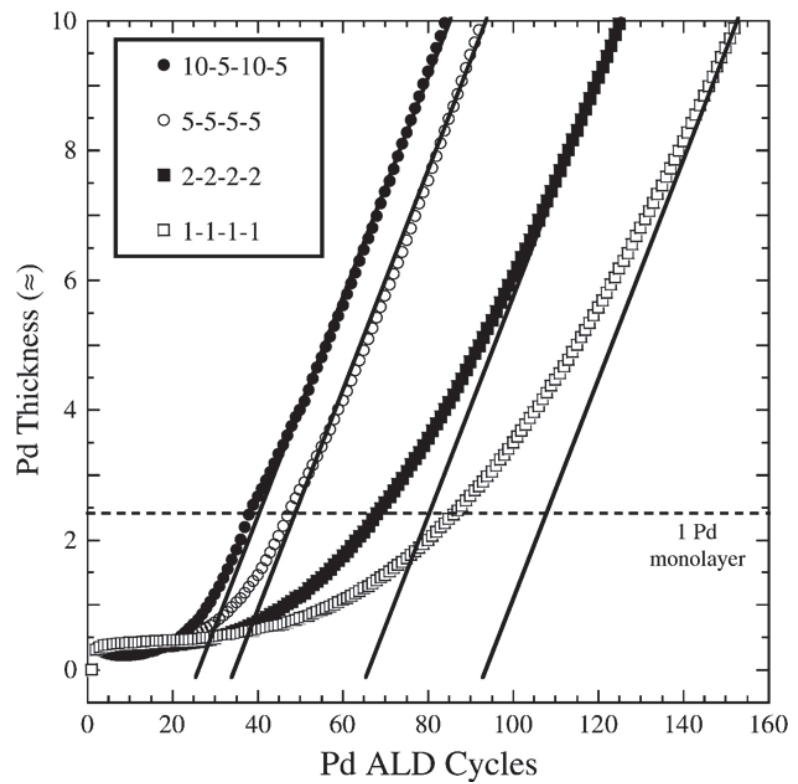

Fig. 4. Nucleation of $\mathrm{Pd}$ on $\mathrm{Al}_{2} \mathrm{O}_{3}$ using different $\mathrm{Pd}$ ALD timing sequences measured by in situ QCM. The timing sequence numbers designate the Pd precursor dose time, $\mathrm{Pd}$ precursor purge time, $\mathrm{HCOH}$ dose time, and $\mathrm{HCOH}$ purge time, respectively, in seconds. ${ }^{7}$

\subsection{Control of ALD Pd particle size}

In many heterogeneous and electro-catalytic reactions, particle size plays a major role in determining catalyst performance. 15 Therefore, a synthesis method which can precisely tune 
the size of noble metal nanoparticles while maintaining a narrow size distribution can improve the catalytic performance significantly. ALD provides fine control over noble metal nanoparticle size. For instance, the size of $\mathrm{Pd}$ nanoparticles on an $\mathrm{Al}_{2} \mathrm{O}_{3}$ support was found to vary linearly between $1.1( \pm 0.5) \mathrm{nm}$ and $2.9( \pm 0.9) \mathrm{nm}$ as the number of Pd ALD cycles was increased from 1 to 25.14 a

The size of noble metal nanoparticles often depends on the metal loading since the nanoparticles form through diffusion which is influenced by the inter-particle spacing. Clearly the Pd loading can be controlled by the number of ALD Pd cycles, but the selflimiting and site-selective nature of ALD provides additional means for controlling the loading. Equation 1 implies that the density of surface hydroxyls dictates the number of adsorbed $\mathrm{Pd}(\mathrm{hfac})_{2}$ precursor molecules during Pd ALD. Therefore, decreasing the surface hydroxyl density should reduce the Pd loading. In agreement with this idea, when the hydroxyl density on an ALD $\mathrm{Al}_{2} \mathrm{O}_{3}$ surface was reduced prior to the Pd ALD through thermal treatment, reaction with alcohols to form surface alkoxides, or reaction with TMA, the Pd loading decreased ${ }^{16}$.

Temperature can also affect nanoparticle size in ALD. In situ QCM measurements demonstrated that $\mathrm{Pd}(\mathrm{hfac})_{2}$ chemisorption on oxide surfaces can occur at temperatures as low as $80^{\circ} \mathrm{C}$, far below the minimum temperature of $200^{\circ} \mathrm{C}$ required to strip the remaining hfac ligands using $\mathrm{HCOH} .14 \mathrm{a}, 17$ This finding suggested that one route to smaller $\mathrm{Pd}$ nanoparticles is to chemisorb the $\mathrm{Pd}(\mathrm{hfac})_{2}$ at lower temperatures to reduce agglomeration. Indeed, low-temperature deposition of $\mathrm{Pd}(\mathrm{hfac})_{2}$ yielded a particle size of $0.8 \pm 0.2 \mathrm{~nm}$, significantly below the $1.4 \pm 0.4 \mathrm{~nm}$ size obtained using the standard $200^{\circ} \mathrm{C} \mathrm{Pd}(\mathrm{hfac})_{2}$ adsorption (Fig. 5). ${ }^{16}$
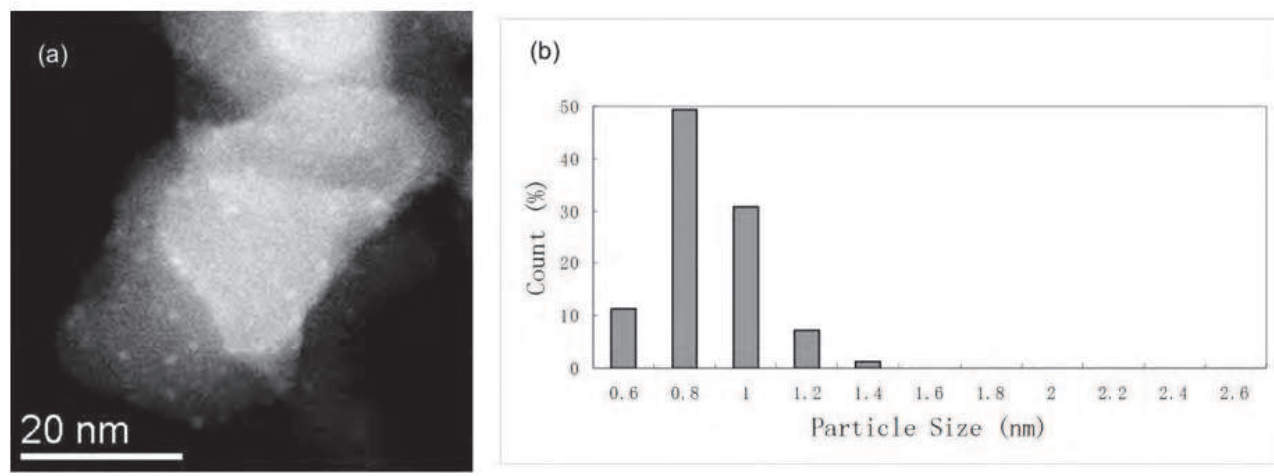

Fig. 5. Scanning transmission electron microscopy (STEM) image (a) and corresponding particle size distribution (b) of ALD Pd sample prepared using $\operatorname{Pd}(\mathrm{hfac})_{2}$ at $100^{\circ} \mathrm{C}$, followed by 2-cycle $\mathrm{ALD} \mathrm{Al}_{2} \mathrm{O}_{3}$ to stabilize the $\mathrm{Pd}(\mathrm{hfac})_{2}$ species before removing the hfac ligands at $200^{\circ} \mathrm{C}$ using $\mathrm{HCOH} .16$

One unique advantage of ALD is the capability to tune the metal loading without affecting the particle size. For instance, when an ethanol exposure was used to remove a fraction of the $\mathrm{Al}_{2} \mathrm{O}_{3}$ surface hydroxyls by conversion to ethoxide species prior to a lowtemperature $\mathrm{Pd}(\mathrm{hfac})_{2}$ exposure, the $\mathrm{Pd}$ loading dropped by $36 \%$, but the $\mathrm{Pd}$ particle size 
was unchanged.16 In contrast, the Pd loading was found to increase substantially when the conventional $\mathrm{Pd}(\mathrm{hfac})_{2} / \mathrm{HCOH}$ reaction scheme was replaced with a novel $\mathrm{Pd}(\text { hfac })_{2} / \mathrm{TMA} / \mathrm{H}_{2} \mathrm{O}$ sequence for Pd ALD. In this case, the $\mathrm{Al}_{2} \mathrm{O}_{3}$ that formed during the interposed TMA $/ \mathrm{H}_{2} \mathrm{O}$ exposures continuously provided new nucleation sites for $\mathrm{Pd}(\mathrm{hfac})_{2}$ chemisorption. Simultaneously, the TMA acted as a reducing agent to remove the hfac ligands. In this way the Pd metal loading from $15 \mathrm{Pd}(\mathrm{hfac})_{2}$ exposures increased from $0.7 \%$ to $6.6 \%$ using this novel pulsing sequence while maintaining a $\mathrm{Pd}$ nanoparticle size of only $\sim 1 \mathrm{~nm} .{ }^{17}$

\subsection{Activity of ALD Pd catalysts}

The catalytic activity of ALD Pd nanoparticles was evaluated using the methanol decomposition reaction. The low-temperature decomposition of methanol to form carbon monoxide and hydrogen may provide a valuable source of hydrogen for transportation fuel, ${ }^{18}$ and $\mathrm{Pd}$ is one of the most active species for catalyzing this process. It is generally believed that smaller Pd particles are more active for methanol decomposition. ${ }^{19}$ In keeping with this trend, Fig. 6 shows that at the same space velocity (mol of methanol per gram of $\mathrm{Pd})$, the activities of the ALD Pd catalysts increase in the sequence: Pd $(2.2 \mathrm{~nm})<\mathrm{Pd}(1.4$ $\mathrm{nm})<\mathrm{Pd}(0.8 \mathrm{~nm})$. It is worth noting that the hydrogen production rate of the $1.4 \mathrm{~nm}$ ALD Pd catalyst at a space velocity of $120000 \mathrm{~mL} / \mathrm{h} / \mathrm{g}$-cat was significantly higher than some of the most active Pd-based catalysts reported for this reaction which is likely due to the highly uniform dispersion and small particle size.

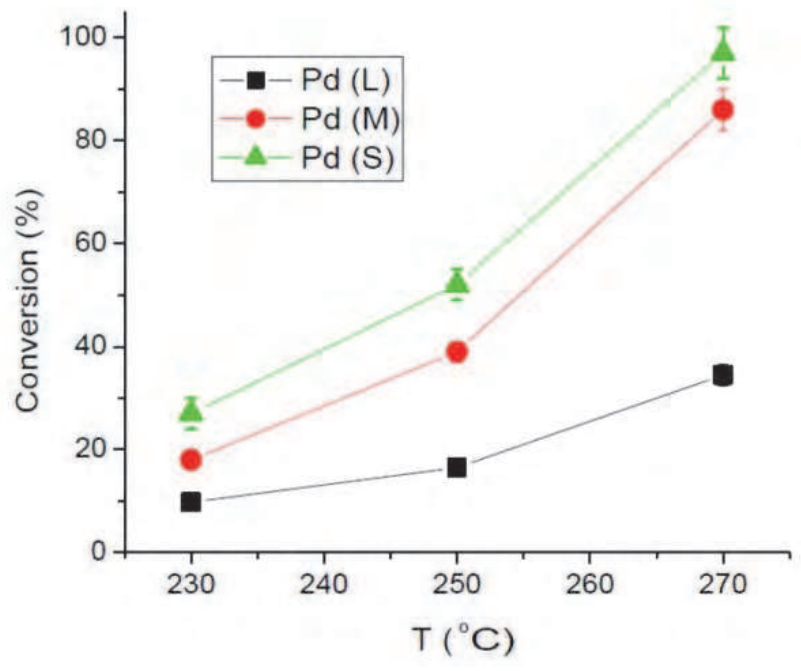

Fig. 6. Conversion of ALD Pd containing small $(0.8 \mathrm{~nm})$, medium $(1.4 \mathrm{~nm})$, and large $(2.2 \mathrm{~nm})$ nanoparticles measured in methanol decomposition. ${ }^{16}$

\subsection{Support effects for ALD Pd catalysts}

The catalytic behavior of noble metal nanoparticles can be greatly influenced by the underlying support material. For instance, cationic $\mathrm{Pd}$ species (most likely $\mathrm{Pd}^{+}$) formed 
through the strong metal-support interaction are sometimes invoked to explain the higher activities of smaller Pd particles supported on $\mathrm{CeO}_{2}$ or $\mathrm{ZrO}_{2} \cdot{ }^{20}$ However, support effects are difficult to isolate using traditional catalyst synthesis methods. These methods rely on bulk supports which often have different physical properties such as surface area, pore size distribution, or particle size that can also affect performance. In contrast, ALD can be used to prepare the support as a thin $(\sim 1 \mathrm{~nm})$, conformal layer on a template (Fig. 3). In this way, the same template can be used for a variety of ALD support layers allowing the composition to be varied while keeping the physical structure constant. ALD Pd nanoparticle catalysts were prepared on $\mathrm{ALD} \mathrm{Al}_{2} \mathrm{O}_{3}, \mathrm{ZrO}_{2}$, and $\mathrm{TiO}_{2}$ layers on high surface area silica gel templates. The $\mathrm{Pd}$ loading was found to vary somewhat with the support layer $\left(1.69 \%\right.$ on $\mathrm{Al}_{2} \mathrm{O}_{3}, 0.82 \%$ on $\mathrm{ZrO}_{2}$, and $1.17 \%$ on $\mathrm{TiO}_{2}$ ) and this probably reflects the different reactivity of the $\mathrm{Pd}(\mathrm{hfac})_{2}$ precursor on these different surfaces. The relative rates of the three catalysts were evaluated for the methanol decomposition reaction, and the absolute rates were divided by the catalyst loading. The relative rates were found to increase as: $\mathrm{Al}_{2} \mathrm{O}_{3}<\mathrm{TiO}_{2}<\mathrm{ZrO}_{2}$ as shown in Fig. 621. On a per-atom basis, the ALD Pd is $7 x$ more active on the ALD $\mathrm{ZrO}_{2}$ support compared to the $\mathrm{ALD} \mathrm{Al}_{2} \mathrm{O}_{3}$ support.

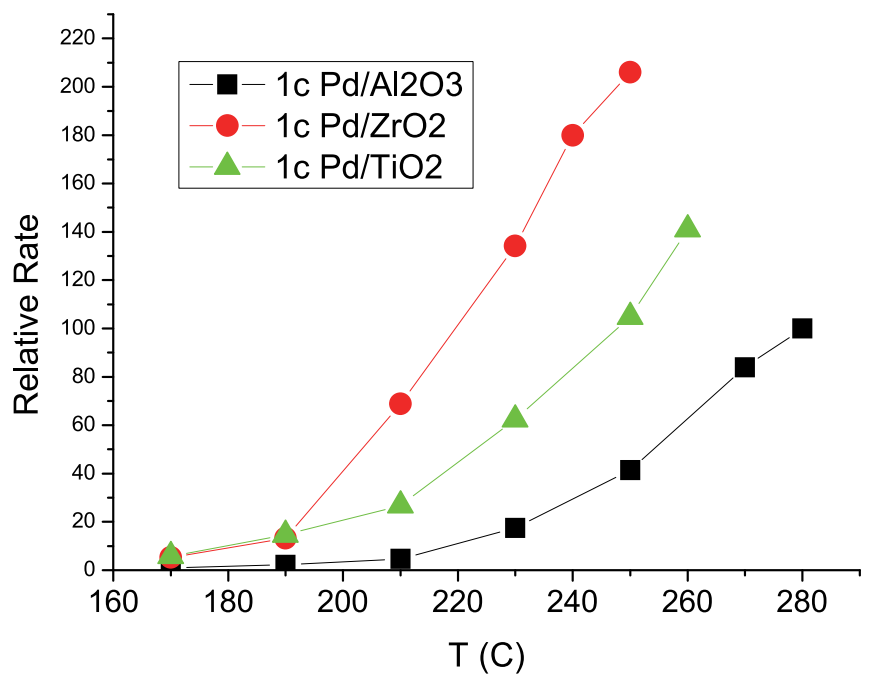

Fig. 7. Influence of metal oxide support on relative rate of methanol decomposition for ALD Pd catalysts.

\section{Platinum ALD}

Platinum (Pt) nanoparticles were first used as industrial catalysts by Vladimir Haensel at UOP in the 1940s ${ }^{22}$. Since then, Pt nanoparticles have become one of the predominant industrial precious metal catalysts and have received significant academic and industrial attention because of their unique catalytic properties. Supported $\mathrm{Pt}$ nanoparticles in the range of sub-nm to a few $\mathrm{nm}$ are effective for oxidative dehydrogenation of propane 23 , water-gas shift reaction 24 , fuel cells 25 , direct conversion of methane 26 , bio-mass 
reforming ${ }^{27}$, and emission control ${ }^{28}$. The high market price of platinum and high activity of under-coordinated surface $\mathrm{Pt}$ atoms have motivated efforts to synthesize small $\mathrm{Pt}$ nanoparticles with a narrow size distribution using conventional preparation methods such as wet impregnation 29 and colloidal chemistry ${ }^{30}$. In light of the results presented above for $\mathrm{Pd}, \mathrm{ALD}$ is a promising technique to prepare monodispersed $\mathrm{Pt}$ nanoparticles on high surface area supports with precise size control.

$\mathrm{Pt}$ ALD is typically conducted using alternating exposures of (trimethyl) methylcyclopentadienyl platinum (IV) ( $\mathrm{MeCpPtMe}_{3}$ ) and oxygen at $300{ }^{\circ} \mathrm{C}$ with dose and purge times of several seconds required to coat planar surfaces. To prepare $\mathrm{Pt}$ nanoparticles on high surface area supports, longer dose and purge times of several minutes are needed to allow complete saturation and precursor removal. Similar to Pd, Pt ALD on oxide surfaces can be divided into two regimes: nucleation and growth. The growth regime is characterized by a constant growth per cycle because the surface reactions have achieved a steady state. The mechanism for Pt ALD in the steady-state growth regime has been well studied and is given by ${ }^{31}$ :

$$
\begin{gathered}
2(\mathrm{MeCp}) \mathrm{PtMe}_{3}+3 \mathrm{O}^{*} \rightarrow 2(\mathrm{MeCp}) \mathrm{PtMe}_{2}{ }^{*}+\mathrm{CH}_{4}+\mathrm{CO}_{2}+\mathrm{H}_{2} \mathrm{O} \\
2\left(\mathrm{MeCp} \mathrm{PtMe}_{2}{ }^{*}+24 \mathrm{O}_{2} \rightarrow 2 \mathrm{Pt}^{*}+3 \mathrm{O}^{*}+16 \mathrm{CO}_{2}+13 \mathrm{H}_{2} \mathrm{O}\right.
\end{gathered}
$$

In reaction 3, $\mathrm{MeCpPtMe}_{3}$ reacts with oxygen adsorbed on the $\mathrm{Pt}$ surface from the preceding $\mathrm{O}_{2}$ exposure. In reaction $4, \mathrm{O}_{2}$ serves to combust the remaining ligands on the adsorbed precursor, and some oxygen remains adsorbed on the surface. Pt ALD in the steady state regime is facilitated by the dissociation of $\mathrm{O}_{2}$ on $\mathrm{Pt}$ to produce the necessary $\mathrm{O}^{*}$ species. In contrast, we expect that Pt nucleation on oxide surfaces should be hindered because most oxides are not capable of dissociating $\mathrm{O}_{2}$ at these temperatures.

\subsection{Pt on $\mathrm{SrTiO}_{3}$}

To study Pt nucleation and growth on a catalytically relevant metal oxide surface, Bedzyk and coworkers prepared $\mathrm{Pt}$ nanoparticles on $\mathrm{SrTiO}_{3}$ (001) single crystals 32 and high surface area $\mathrm{SrTiO}_{3}$ nanocubes ${ }^{3}$. Contrary to expectations, the Pt growth during the nucleation period on $\mathrm{SrTiO}_{3}(001)$ was $\sim 2$ x higher than in the steady-state regime (Fig. 8). The higher initial growth was attributed to a greater density of reactive sites on $\mathrm{SrTiO}_{3}$ compared to Pt. In contrast to the Pd study which used relatively short exposure times and showed a lower initial growth (Fig. 4), the Pt nucleation in Fig. 8 used much larger precursor exposures that were sufficient to saturate the surface reactions despite a lower reaction rate. Atomic force microscopy and scanning electron microcopy (SEM) revealed that the Pt nucleation occurred by island coalescence on the $\mathrm{SrTiO}_{3}(001)$ surface, and the diameter of the Pt nanoparticles increased linearly with Pt ALD cycles before achieving film closure at $\sim 40$ cycles. This observation matches the transition between the nucleation and growth regimes in Fig. 8, and supports the hypothesis that the Pt grows faster on the $\mathrm{SrTiO}_{3}$ (001) substrate. Grazing-incidence small angle X-ray scattering (GISAXS) was utilized to study the evolution in surface morphology with increasing Pt ALD cycles and showed that both the Pt nanoparticle size and inter-particle distance increased linearly with the number of cycles. 


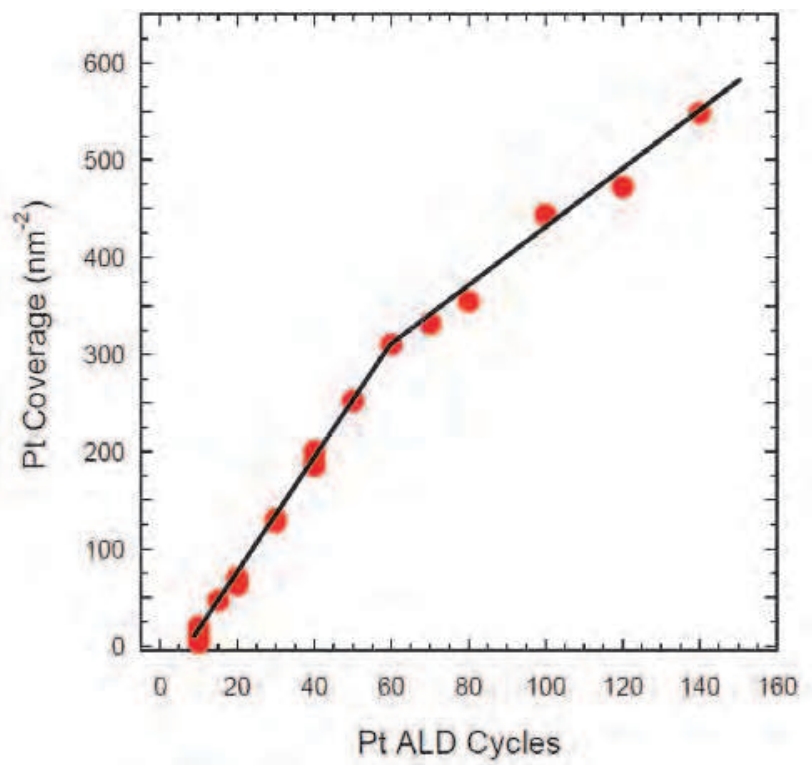

Fig. 8. ALD Pt coverage on $\mathrm{SrTiO}_{3}$ (001)versus Pt ALD cycles.
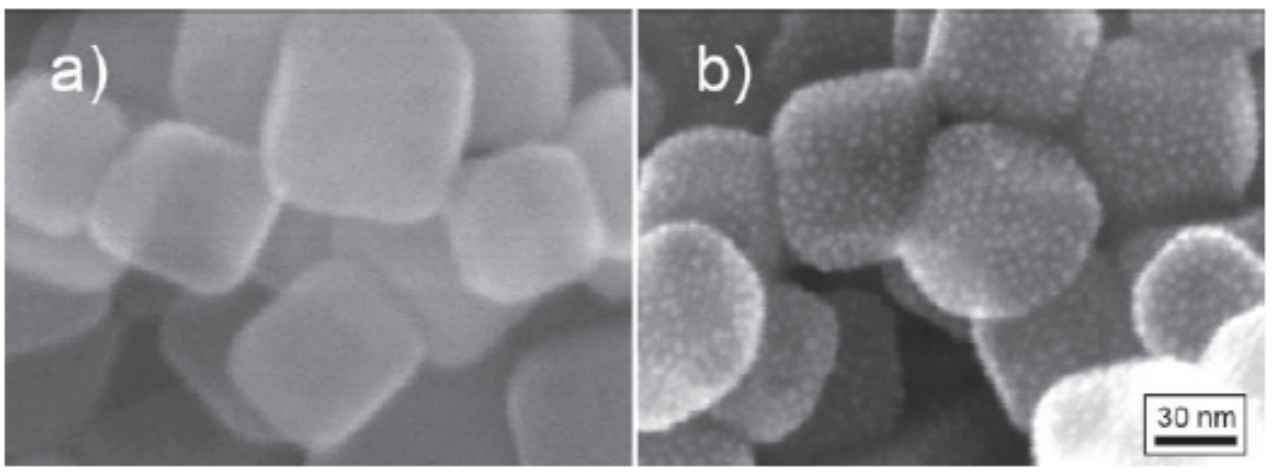

Fig. 9. SEM images of $\mathrm{SrTiO}_{3}$ nanocubes before (a) and after (b) three Pt ALD cycles.

The surface area of the single crystal $\mathrm{SrTiO}_{3}(001)$ substrate was far too low to facilitate catalytic testing by conventional methods. However, the surface reactions for Pt ALD should be independent of substrate morphology. Using this assumption, $\mathrm{Pt}$ was deposited on high surface area $\left(20 \mathrm{~m}^{2} / \mathrm{g}\right) \mathrm{SrTiO}_{3}$ nanocubes with a size of $\sim 60 \mathrm{~nm}$ that were predominantly terminated with (001) facets. SEM images of the resulting materials revealed monodispersed Pt nanoparticles supported on the $\mathrm{SrTiO}_{3}$ nanocubes (Fig. 9). During the early stages of $\mathrm{Pt} A L D$ on the $\mathrm{SrTiO}_{3}$ nanocubes the mass was found to increase by $4.4 \mathrm{wt} \%$ per cycle, $2 \mathrm{x}$ higher than the value predicted using the steady-state growth rate for Pt of $\sim 0.5 \AA$ per cycle $33,31 \mathrm{~b}$. Evidently, the enhanced Pt uptake observed during nucleation on the $\mathrm{SrTiO}_{3}$ single crystal also occurs on nanophase $\mathrm{SrTiO}_{3}$, 
suggesting that the $\mathrm{Pt}$ ALD is indeed independent of substrate morphology. X-ray scattering showed that both the Pt nanoparticle size and inter-particle spacing increased linearly with the number of Pt ALD cycles, consistent with the single crystal results and supporting a diffusional processes for nanoparticle formation. Figure 10 shows the size of the ALD Pt nanoparticles as determined from line broadening of the $\mathrm{Pt}(111)$ peak using wide angle X-ray scattering measurements. As with Pd, the ALD Pt nanoparticle size could be controlled precisely in the nm regime by adjusting the number of ALD cycles. The ALD Pt nanoparticles supported on $\mathrm{SrTiO}_{3}$ nanocubes were significantly more active for propane oxidation than comparable catalysts prepared on a $\mathrm{\gamma}-\mathrm{Al}_{2} \mathrm{O}_{3}$ support, emphasizing the important role played by the support ${ }^{36}$.

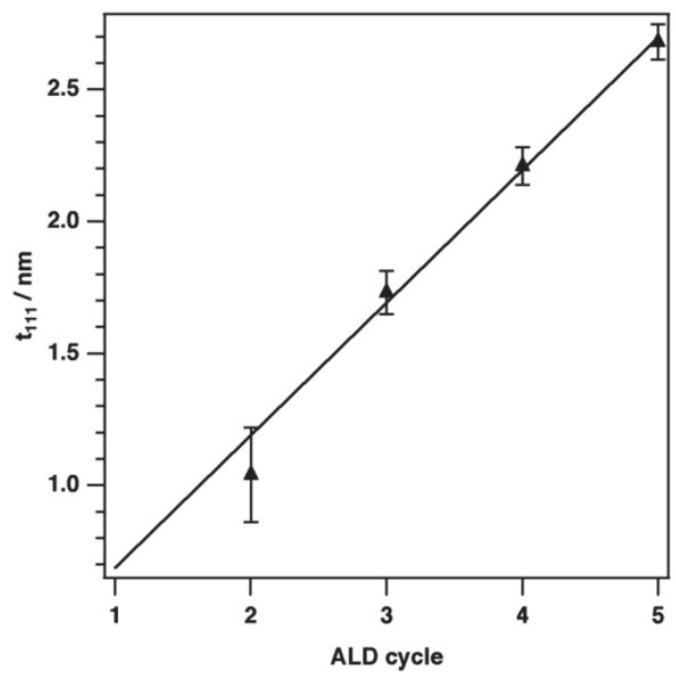

Fig. 10. Pt nanoparticle size on $\mathrm{SrTiO}_{3}$ nanocubes versus Pt ALD cycles as determined using X-ray diffraction.

\subsection{In-situ X-ray absorption studies of Pt ALD}

A detailed understanding of the surface chemistry for noble metal ALD can lead to better methods for controlling the nanoparticle size, composition, and dispersion. X-ray absorption spectroscopy (XAS), is a powerful tool for determining the local geometric and electronic structure of materials under typical ALD process conditions. Marshall and co-workers used in situ XAS to study Pt ALD over $\gamma-\mathrm{Al}_{2} \mathrm{O}_{3}, \mathrm{TiO}_{2}$, and $\mathrm{SrTiO}_{3}$ surfaces ${ }^{34}$. In situ XAS measurements performed at the $\mathrm{Pt} \mathrm{L}_{3}$ edge $(11.56 \mathrm{KeV})$ identified adsorbed $\mathrm{MeCpPtMe}_{2}$, $\mathrm{PtO}$, and metallic $\mathrm{Pt}$ as the predominant surface species present during Pt ALD. Timeresolved XAS measurements revealed the detailed evolution of these species during $\mathrm{Pt}$ nucleation (Fig. 11a) allowing a mechanism to be proposed for the surface reactions (Fig 11b). During the first Pt precursor exposure (Pt dose 1), $\mathrm{MeCpPtMe}_{3}$ reacts with surface hydroxyl groups but remains essentially intact. The subsequent $\mathrm{O}_{2}$ exposure at $100-300{ }^{\circ} \mathrm{C}$ converts all of the adsorbed $\mathrm{MeCpPtMe}_{2}$ into $\mathrm{PtO}\left(\mathrm{O}_{2}\right.$ dose 1$)$. In the second Pt ALD cycle, $\mathrm{MeCpPtMe}_{3}$ chemisorbs first on surface hydroxyl groups, and then later on the $\mathrm{PtO}$ as 
evidenced by the decrease in $\mathrm{PtO}$ and simultaneous increase in $\mathrm{Pt}$ metal during the later portion of $\mathrm{Pt}$ dose 2 . The following $\mathrm{O}_{2}$ exposure again converts all of the adsorbed species to $\mathrm{PtO}\left(\mathrm{O}_{2}\right.$ dose 2). Apparently, no surface hydroxyls remain for the third and final Pt ALD cycle, because the $\mathrm{MeCpPtMe}_{3}$ exposure ( $\mathrm{Pt}$ dose 3 ) immediately causes a decrease in $\mathrm{PtO}$ concentration and a simultaneous increase in $\mathrm{Pt}$ metal in a 1:1 ratio.

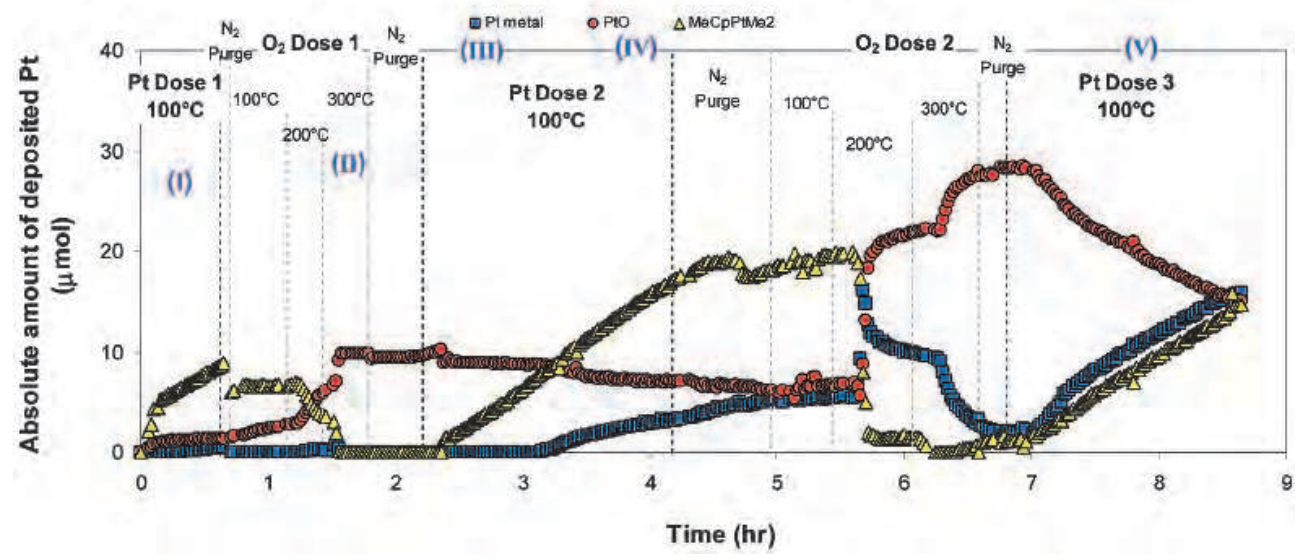

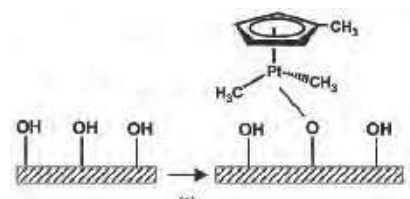

(I)

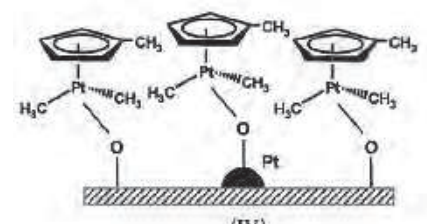

(IV)

(a)

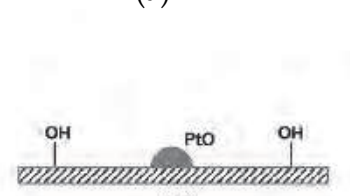

(II)

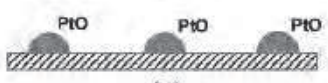

(V)

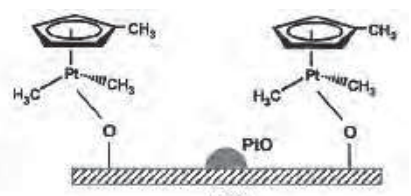

(III)

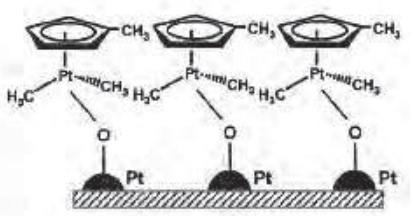

(IV)

(b)

Fig. 11. (a) Concentration of $\mathrm{Pt}$ species on $\gamma-\mathrm{Al}_{2} \mathrm{O}_{3}$ during $3 \mathrm{Pt} A L D$ cycles as determined using in situ XAS measurements. (b) Mechanism proposed for Pt ALD on $\gamma-\mathrm{Al}_{2} \mathrm{O}_{3}$.

\section{ALD of mixed-noble metal catalysts}

Bimetallic catalysts offer the possibility to combine the unique advantages of each component, allowing the catalytic properties to be tuned by adjusting the nanoparticle composition and structure. However, the design and economical synthesis of catalysts at the atomic scale represents a scientific Grand Challenge ${ }^{35}$. ALD offers a potential solution to this challenge. As with the pure $\mathrm{Pd}$ and $\mathrm{Pt}$ nanoparticles described above, the size of bimetallic particles should be controlled by the total number of ALD cycles performed. Moreover, the composition will be 
dictated by the relative number of ALD cycles used for each component. Finally, the structure of the bimetallic nanoparticles might be controlled by the order in which the individual cycles are executed. One of the appeals of ALD for the atom scale synthesis of bimetallics is that once a procedure is developed to create the desired nanoparticles, the same process can be used to deposit them on virtually any substrate, and at any quantity.

\subsection{ALD of iridium-platinum films}

To demonstrate the viability of mixed-noble metal ALD, Elam and coworkers synthesized thin-film mixtures of iridium and platinum using iridium (III) acetylacetonate $-\mathrm{O}_{2}$ cycles for Ir ALD and $\mathrm{MeCpPtMe}_{3}-\mathrm{O}_{2}$ cycles for Pt ALD at $300{ }^{\circ} \mathrm{C} 9$. In situ QCM measurements were performed using various Ir:Pt dosing ratios. These measurements found that the growth rates of Pt and Ir remained constant regardless of the dosing ratio, indicating that both the Ir and Pt ALD proceed equally well on either metal surface. This allowed the composition of the Ir-Pt mixed metal films to be easily controlled using the relative number of Ir cycles, and predicted using a simple rule-of-mixtures formula (Fig. 12). The lattice parameter for the IrPt thin films was determined using X-ray diffraction measurements and was found to vary smoothly between the values of the pure $\mathrm{Ir}$ and $\mathrm{Pt}$ as the composition was adjusted, consistent with well-mixed, bimetallic alloys. Using this method, conformal Ir-Pt films were deposited successfully on high aspect ratio surfaces, suggesting that coating porous materials using this method should be feasible.

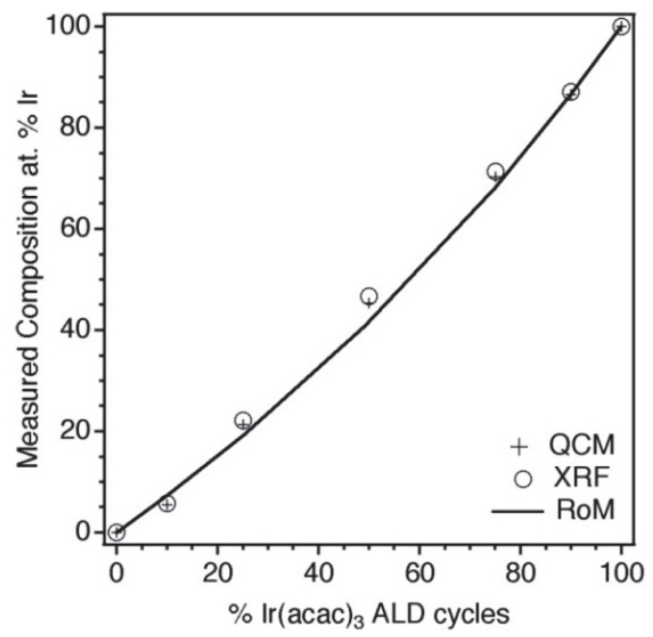

Fig. 12. Composition of ALD Ir-Pt films versus percentage of Ir ALD cycles measured by quartz crystal microbalance (QCM) and X-ray fluorescence (XRF), and predicted using the rule-of-mixtures (RoM).

\subsection{ALD of platinum-ruthenium nanoparticles}

Pt-Ru mixed-metal films were prepared using $\mathrm{MeCpPtMe}_{3}-\mathrm{O}_{2}$ cycles for Pt ALD and 2,4(dimethylpentadienyl)(ethylcyclopentadienyl) ruthenium (II) (Ru(DER)) - $\mathrm{O}_{2}$ cycles for $\mathrm{Ru}$ $\mathrm{ALD}$ at $300^{\circ} \mathrm{C}{ }^{36}$. Similar to the bimetallic Ir-Pt thin films, the growth rates of the $\mathrm{Pt}$ and $\mathrm{Ru}$ 
measured by QCM during the Pt-Ru mixed-metal ALD were in close agreement with the growth rates of the pure ALD Pt and $\mathrm{Ru}$. Next, $\mathrm{Pt}-\mathrm{Ru}$ nanoparticles were synthesized using 2 cycles $\mathrm{Ru}(\mathrm{DER}) / \mathrm{O}_{2} ; 1$ cycle $\mathrm{MeCpPtMe} / \mathrm{O}_{2}$; and 1 cycle $\mathrm{Ru}(\mathrm{DER}) / \mathrm{O}_{2}$ over spherical $\mathrm{Al}_{2} \mathrm{O}_{3}$ nanopowder with a surface area of $\sim 35 \mathrm{~m}^{2} / \mathrm{g}$ yielding an average particle size of $1.2 \pm 0.3$ $\mathrm{nm}$. Figure 13 shows the results of XAS measurement performed at the Ru K-edge (22.12 $\mathrm{KeV})$. The Ru K-edge of Ru-Pt nanoparticles is shifted by $\sim 3 \mathrm{eV}$ to higher energy compared to the $\mathrm{Ru} / \mathrm{SiO}_{2}$ standard, suggesting the formation of bimetallic Pt-Ru. Furthermore, the magnitude of the Fourier transform of the $\mathrm{Ru}$ K-edge for the Ru-Pt nanoparticles clearly shows different features compared to the Ru nanoparticle standard, indicating the existence of $\mathrm{Pt}$ atoms in the first coordination shell of the $\mathrm{Ru}$. Ru K-edge fitting yielded coordination numbers of 3.8 for Ru-Ru and 4.5 for Ru-Pt. These measurements were sufficient to confirm that the nanoparticles were bimetallic, but structure determination (core-shell versus alloy) would require XAS data for the Pt K-edge. The Ru-Pt nanoparticles supported on spherical $\mathrm{Al}_{2} \mathrm{O}_{3}$ nanopowder exhibited a much higher reactivity in the methanol decomposition reaction compared to a physical mixture of $\mathrm{Ru}$ and $\mathrm{Pt}$ monometallic catalysts, consistent with the unique atomic arrangement of a bimetallic catalyst.
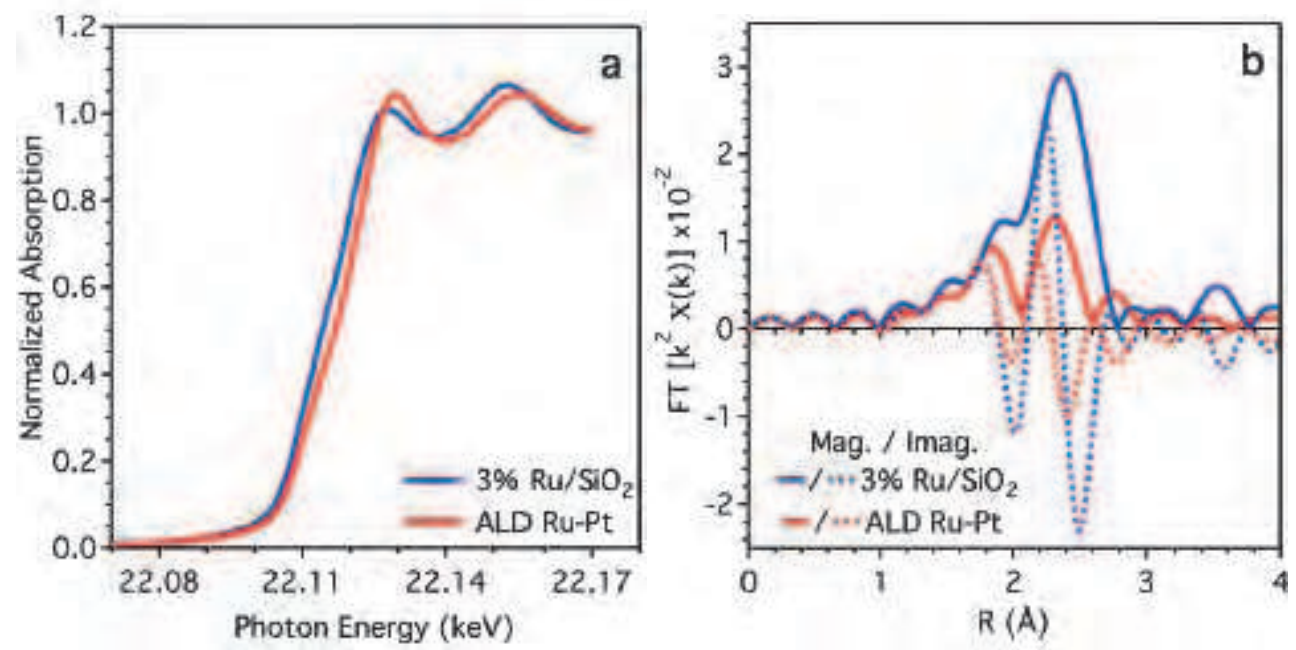

Fig. 13. XAS measurements showing (a) Ru K-edge for ALD Ru-Pt/ $\mathrm{Al}_{2} \mathrm{O}_{3}$ and a reference $3 \% \mathrm{Ru} / \mathrm{SiO}_{2}$; (b) Fourier transforms of the absorption spectra where the solid lines show the magnitude and the broken lines shows the imaginary part.

\subsection{ALD of platinum-palladium nanoparticles}

Pt-Pd mixed-metal nanoparticles $\sim 1 \mathrm{~nm}$ diameter were synthesized over ALD modified $\mathrm{SiO}_{2}$ gel with a surface area of $100 \mathrm{~m}^{2} / \mathrm{g}$ using $\mathrm{MeCpPtMe}_{3}-\mathrm{O}_{2}$ cycles for Pt ALD and Pd(hfac) $)_{2}-$ $\mathrm{HCOH}$ cycles for Pd ALD. The composition of the Pt-Pd nanoparticles could be adjusted in two ways. Due to the different reaction kinetics for the Pt and Pd ALD processes, the Pt metal loading could be varied by adjusting the deposition temperature while the Pd loading remained constant with temperature. Consequently, the Pt-Pd composition could be controlled through the deposition temperature. In addition, the composition could be tuned 
using the ratio of $\mathrm{Pt}$ to $\mathrm{Pd} \mathrm{ALD}$ cycles. The scanning transmission electron microscopy (STEM) image in Fig. 14a illustrates the homogeneity of the as-prepared Pt-Pd mixed-metal nanoparticles prepared using a 1:1 molar ratio supported by $\mathrm{ALD} \mathrm{Al}_{2} \mathrm{O}_{3}$-coated $\mathrm{SiO}_{2}$ gel. The mean size of the as-prepared Pt-Pd nanoparticles synthesized using one Pt ALD cycle followed by one Pd ALD cycle was $1.1 \pm 0.2 \mathrm{~nm}$. After $3.5 \% \mathrm{H}_{2}$ treatment at $250{ }^{\circ} \mathrm{C}$ for one hour, the particle size did change appreciably (Fig. 14b), indicating a high thermal stability for the Pt-Pd nanoparticles.

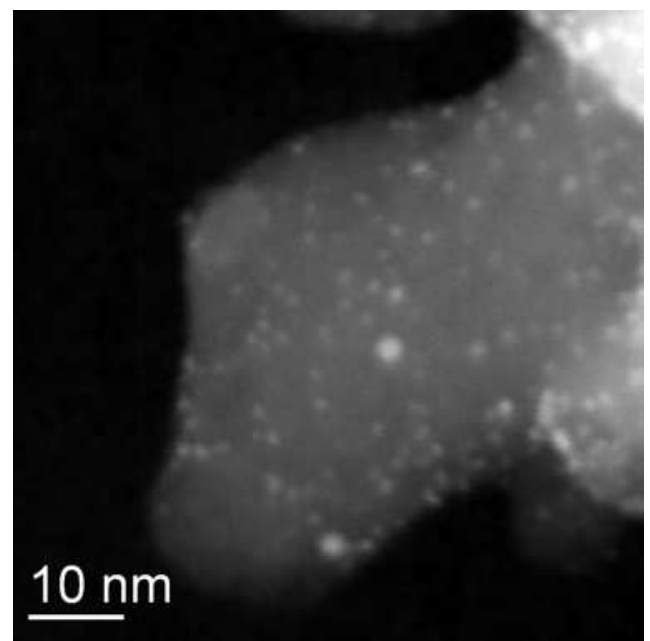

(a)

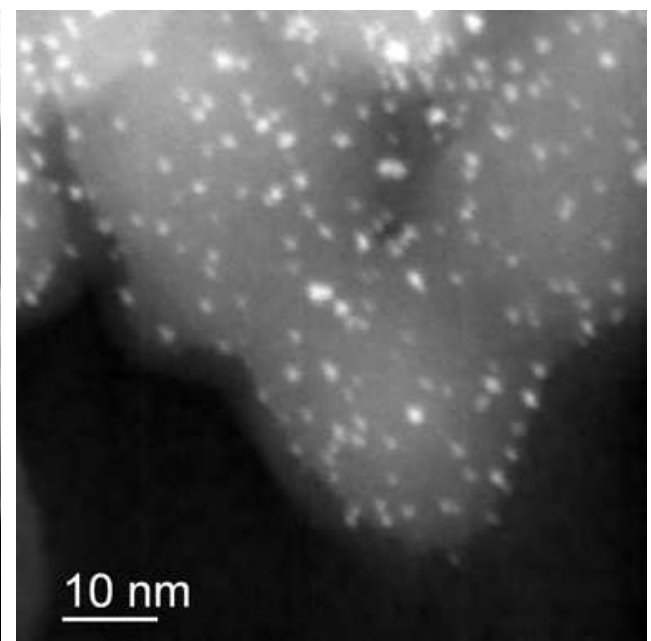

(b)

Fig. 14. STEM images of Pt-Pd nanoparticles supported on $\mathrm{ALD} \mathrm{Al}_{2} \mathrm{O}_{3}$-coated $\mathrm{SiO}_{2}$ gel. (a) as-prepared, (b) after $\mathrm{H}_{2}$ treatment at $250{ }^{\circ} \mathrm{C}$ for one hour.

The structure of the ALD Pt-Pd nanoparticles was investigated using XAS measurements at both the $\mathrm{Pt}_{3}$ edge $(11.56 \mathrm{KeV})$ and the $\mathrm{Pd} \mathrm{K}$ edge $(24.35 \mathrm{KeV})$. The as-prepared samples were reduced in $\mathrm{H}_{2}$ at $250{ }^{\circ} \mathrm{C}$ for one hour to obtain a fully metallic state prior to performing the XAS measurements. Small shifts in the edge position and changes in shape for both the $\mathrm{Pt}$ and Pd edges were clearly observed. Significant changes in the magnitude and imaginary part of both the Pt and Pd extended X-ray absorption fine structure (EXAFS) measurements indicated second scatterers in the first shell structure, i.e., a bimetallic nanoparticle. Furthermore, EXAFS model fitting showed that Pt-Pd forms a Pt-core, Pd-shell nanostructure, independent of the preparation temperature and ALD pulse sequence. Density functional theory (DFT) was used to calculate the lowest energy configuration for the Pt-Pd binary system. In vacuum, there was no clear preference for either a Pt- or Pd-rich surface. However, the Pd-rich surface was found to be the most stable with one monolayer of hydrogen adsorbed, in good agreement with EXAFS results ${ }^{37}$.

\section{Stabilization of noble metal nanoparticles}

The stability of small particles against sintering is a serious problem limiting the application of metal nanoparticles. This problem is particularly severe for supported noble metal catalysts where sintering at high temperatures is a major contributor to 
catalyst deactivation. ${ }^{38 a-d}$ Various methods have been developed to encapsulate noble metal nanoparticles in porous materials using techniques such as chemical vapor deposition, grafting, micro-emulsion, and dendrimer encapsulation to form core-shell structures. ${ }^{39 a-h}$ Some of these encapsulated nanoparticles showed good sintering resistance up to $800^{\circ} \mathrm{C}$. However, in nearly all cases the catalytic activity was greatly reduced due to the mass transfer resistance imposed by the protective shell (usually tens of nm thick). In contrast to these previous methods, ALD should enable precise control over the thickness of the protective layer to achieve an optimum balance between enhanced stability and increased mass transfer resistance.

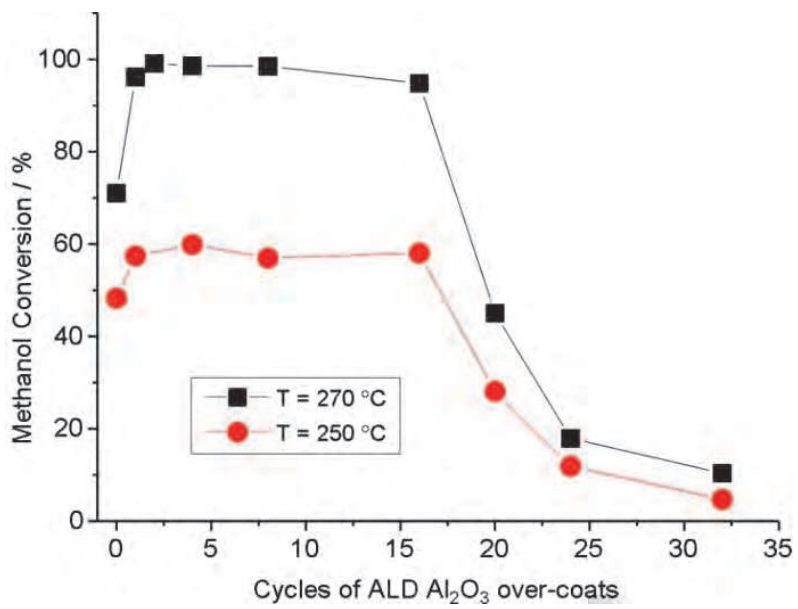

Fig. 15. Methanol conversion for Pd catalysts with 0 to 32 cycles of $\mathrm{ALD}^{-} \mathrm{Al}_{2} \mathrm{O}_{3}$ over-coating in the methanol decomposition reaction carried out at 250 and $270{ }^{\circ} \mathrm{C} .40$

To explore this possibility, $\mathrm{Al}_{2} \mathrm{O}_{3}$ ALD was used to form protective "over-coats" on ALD Pd nanoparticle catalysts. The catalytic activity and stability of the over-coated catalysts were evaluated using the methanol decomposition reaction. Surprisingly, up to a certain thickness formed using $16 \mathrm{ALD}^{\mathrm{A}} \mathrm{O}_{3}$ cycles, the protective layers preserved or even slightly enhanced the catalytic activity compared to the same catalyst without $\mathrm{Al}_{2} \mathrm{O}_{3}$ overcoating (Fig. 15). ${ }^{40}$ The reason for this behavior was revealed through infrared spectroscopic measurements of adsorbed $\mathrm{CO}$ designed to probe the $\mathrm{Pd}$ surface. These measurements showed that the $\mathrm{ALD} \mathrm{Al}_{2} \mathrm{O}_{3}$ over-coats preferentially nucleate at $\mathrm{Pd}$ corners, steps, and edges while leaving the catalytically active Pd (111) facets accessible for methanol conversion. An additional benefit of the over-coating was that the defect sites where the $\mathrm{Al}_{2} \mathrm{O}_{3}$ preferentially formed were also responsible for the undesired catalytic reaction to form coke. Consequently, the selectivity of the Pd catalyst for methanol decomposition could be controlled by the site-specific over-coating treatment to preferentially form $\mathrm{CO}$ and $\mathrm{H}_{2}$ versus coke.

In addition to these changes in catalytic behavior, the $\mathrm{ALD} \mathrm{Al}_{2} \mathrm{O}_{3}$ over-coats virtually eliminated the nanoparticle sintering exhibited by the uncoated Pd catalysts at elevated temperatures. The fact that the $\mathrm{Pd}$ surfaces were still accessible to the methanol and the $\mathrm{CO}$ probe molecules even after $8 \mathrm{ALD} \mathrm{Al}_{2} \mathrm{O}_{3}$ cycles indicates that the $\mathrm{ALD} \mathrm{Al}_{2} \mathrm{O}_{3}$ over-coats are 
porous. To understand this behavior, the mechanism for $\mathrm{Al}_{2} \mathrm{O}_{3}$ ALD on Pd surfaces was investigated by combing in situ QCM and QMS experimental studies with density functional theory (DFT) calculations. ${ }^{37}$ Both the experimental results and DFT calculations indicated that when TMA reacts on the Pd surface, $-\mathrm{CH}_{3}{ }^{*}$ surface species are deposited that inhibit further TMA chemisorption. This inhibition likely introduces discontinuities in the $\mathrm{Al}_{2} \mathrm{O}_{3}$ film and gives rise to the porosity. The porosity of the ALD $\mathrm{Al}_{2} \mathrm{O}_{3}$ overcoats could be increased through high temperature treatment or prolonged reaction at elevated temperatures, suggesting that the Pd catalyst might be modified by tuning the porosity of the $\mathrm{Al}_{2} \mathrm{O}_{3}$ over-coats to optimize a particular reaction.

\section{Conclusion}

Atomic layer deposition is a powerful method for catalyst synthesis. The self-limiting surface chemistry of ALD provides digital, sub-nm control over the amount of material deposited and allows nanoporous, high surface area materials to be coated uniformly. Noble metal nanoparticles can be prepared by ALD including $\mathrm{Pd}, \mathrm{Pt}$, Ir, and $\mathrm{Ru}$, that are highly dispersed and uniform, and the size can be controlled easily on the nm scale by adjusting growth parameters such as the number of ALD cycles. By combining the ALD processes for two different noble metals, bimetallic nanoparticles and films and can be synthesized where the composition is dictated by the relative number of ALD cycles used for the two components. The capability to form uniform, continuous, ultrathin films of metal oxide support materials such as $\mathrm{Al}_{2} \mathrm{O}_{3}, \mathrm{TiO}_{2}$, and $\mathrm{ZrO}_{2}$, as well as size-selected catalytic noble metal nanoparticles, allows a catalyst to be fabricated starting from nearly any convenient template through a sequence of ALD processes. ALD can be used to stabilize noble metal nanoparticles while preserving their catalytic activity by forming porous overcoats that limit agglomeration but still permit access to the metal surface. The scale-up of ALD synthesis is straightforward owing to the self-saturating surface reactions and gas-phase precursors, so that novel materials developed in the lab can be manufactured for industrial use. The application of ALD technology to catalyst synthesis is an active area of research, and new capabilities are certain to emerge in the near future.

\section{Acknowledgment}

This material is based upon work supported as part of the Institute for Atom-efficient Chemical Transformations (IACT), an Energy Frontier Research Center funded by the U.S. Department of Energy, Office of Science, Office of Basic Energy Sciences. Y. L. and J. L. were supported in part by the U.S. Department of Energy, BES-HFI, Chemical Sciences under Contract DE-AC-02-06CH11357. Argonne is managed by UChicago Argonne, LLC, for the U.S. Department of Energy under contract DE-AC02-06CH11357.

\section{References}

[1] George, S. M., Atomic Layer Deposition: An Overview. Chemical Reviews 2010, 110, (1), 111-131.

[2] Haukka, S.; Lakomaa, E. L.; Suntola, T., Adsorption controlled preparation of heterogeneous catalysts. In Adsorption And Its Applications In Industry And 
Environmental Protection, Vol I: Applications In Industry, Dabrowski, A., Ed. Elsevier: New York, 1999; Vol. 120, pp 715-750.

[3] Ott, A. W.; Klaus, J. W.; Johnson, J. M.; George, S. M., Al2O3 thin film growth on Si(100) using binary reaction sequence chemistry. Thin Solid Films 1997, 292, (1-2), 135-144.

[4] Elam, J.; Groner, M.; George, S., Viscous flow reactor with quartz crystal microbalance for thin film growth by atomic layer deposition. REVIEW OF SCIENTIFIC INSTRUMENTS 2002, 73, (8), 2981-2987.

[5] Elam, J. W.; Sechrist, Z. A.; George, S. M., ZnO/Al2O3 Nanolaminates Fabricated by Atomic Layer Deposition: Growth and Surface Roughness Measurements. Thin Solid Films 2002, 414, 43-55.

[6] Elam, J. W.; Libera, J. A.; Trang, H. H.; Feng, H.; Pellin, M. J., Atomic Layer Deposition of Al2O3 on Nanoporous Silica Gel Powder. Journal of Physical Chemistry C 2010, 114, 17286-17292.

[7] Elam, J. W.; Zinovev, A.; Han, C. Y.; Wang, H. H.; Welp, U.; Hryn, J. N.; Pellin, M. J., Atomic layer deposition of palladium films on $\mathrm{Al} 2 \mathrm{O} 3$ surfaces. Thin Solid Films 2006, 515, (4), 1664-1673.

[8] Elam, J. W.; George, S. M., Growth of ZnO/Al2O3 Alloy Films Using Atomic Layer Deposition Techniques. Chemistry of Materials 2003, 15, 1020-1028.

[9] Christensen, S. T.; Elam, J. W., Atomic Layer Deposition of Ir-Pt Alloy Films. Chemistry of Materials 2010, 22, (8), 2517-2525.

[10] Igumenov, I. K.; Belosludov, V. R.; Stabnikov, P. A., Frontier trends in the prediction of vapour pressure of metal-organic precursors. Journal De Physique Iv 1999, 9, (P8), 1522.

[11] Senkevich, J. J.; Tang, F.; Rogers, D.; Drotar, J. T.; Jezewski, C.; Lanford, W. A.; Wang, G. C.; Lu, T. M., Substrate-independent palladium atomic layer deposition. Chemical Vapor Deposition 2003, 9, (5), 258.

[12] Ten Eyck, G. A.; Senkevich, J. J.; Tang, F.; Liu, D. L.; Pimanpang, S.; Karaback, T.; Wang, G. C.; Lu, T. M.; Jezewski, C.; Lanford, W. A., Plasma-assisted atomic layer deposition of palladium. Chemical Vapor Deposition 2005, 11, (1), 60.

[13] George, S. M.; Goldstein, D. N., Surface poisoning in the nucleation and growth of palladium atomic layer deposition with $\mathrm{Pd}(\mathrm{hfac})(2)$ and formalin. Thin Solid Films 2011, 519, (16), 5339-5347.

[14] (a) Lu, J. L.; Stair, P. C., Nano/Subnanometer Pd Nanoparticles on Oxide Supports Synthesized by AB-type and Low-Temperature ABC-type Atomic Layer Deposition: Growth and Morphology. Langmuir 2010, 26, (21), 16486-16495; (b) Feng, H.; Elam, J. W.; Libera, J. A.; Setthapun, W.; Stair, P. C., Palladium Catalysts Synthesized by Atomic Layer Deposition for Methanol Decomposition. Chemistry of Materials 2010, 22, (10), 3133-3142.

[15] (a) Astruc, D., Inorg. Chem. 2007, 46, 1884-1894; (b) Astruc, D., Nanoparticles and Catalysis. Wiley-VCH: 2008; (c) Bell, A. T., Sci. 2003, 299, 1688-1691; (d) Chen, M. S.; Goodman, D. W., Catal. Today 2006, 111, (1-2), 22-33; (e) Boutonnet, M.; Lögdberg, S.; Svensson, E. E., Current Opinion in Colloid E Interface Sci. 2008, 13, (4), 270-286; (f) Cuenya, B. R., Thin Solid Films 2010, 518, (12), 3127-3150; (g) Aiken, J. D.; Finke, R. G., J. Mol. Catal. 1999, 145, (1-2), 1-44; (h) Liu, W., China Particuology 2005, 3, (6), 383394. 
[16] Feng, H.; Elam, J. W.; Libera, J. A.; Stair, P. C.; Miller, J. T., Subnanometer Palladium Particles Synthesized by Atomic Layer Deposition. Acs Catalysis 2011, 1, (6), 665-673.

[17] Lu, J. L.; Stair, P. C., Low-Temperature ABC-Type Atomic Layer Deposition: Synthesis of Highly Uniform Ultrafine Supported Metal Nanoparticles. Angewandte ChemieInternational Edition 2010, 49, (14), 2547-2551.

[18] Wilson, M. S., Methanol decomposition fuel processor for portable power applications. International Journal of Hydrogen Energy 2009, 34, (7), 2955-2964.

[19] Saitoh, Y.; Ohtsu, S.; Makie, Y.; Okada, T.; Satoh, K.; Tsuruta, N.; Terunuma, Y., Effect of Pd Dispersion on Methanol Decomposition over Supported Pd-Catalysts. Bulletin of the Chemical Society of Japan 1990, 63, (1), 108-115.

[20] (a) Matsumura, Y.; Okumura, M.; Usami, Y.; Kagawa, K.; Yamashita, H.; Anpo, M.; Haruta, M., Low-temperature decomposition of methanol to carbon monoxide and hydrogen with low activation energy over Pd/ZrO2 catalyst. Catalysis Letters 1997, 44, (3-4), 189-191; (b) Matsumura, Y.; Shen, W. J., Methanol decomposition and synthesis over palladium catalysts. Topics in Catalysis 2003, 22, (3-4), 271-275.

[21] Feng, H.; Elam, J., 2011, in preparation.

[22] Vladimir, H. Alumina-platinum-halogen catalyst and preparation thereof. 2479109 08/16/1949, 1949.

[23] Vajda, S.; Pellin, M. J.; Greeley, J. P.; Marshall, C. L.; Curtiss, L. A.; Ballentine, G. A.; Elam, J. W.; Catillon-Mucherie, S.; Redfern, P. C.; Mehmood, F.; Zapol, P., Subnanometre platinum clusters as highly active and selective catalysts for the oxidative dehydrogenation of propane. Nature Materials 2009, 8, (3), 213-216.

[24] Fu, Q.; Saltsburg, H.; Flytzani-Stephanopoulos, M., Active nonmetallic $\mathrm{Au}$ and Pt species on ceria-based water-gas shift catalysts. Science 2003, 301, (5635), 935-938.

[25] Wasmus, S.; Kuver, A., Methanol oxidation and direct methanol fuel cells: a selective review. Journal of Electroanalytical Chemistry 1999, 461, (1-2), 14-31.

[26] Periana, R. A.; Taube, D. J.; Gamble, S.; Taube, H.; Satoh, T.; Fujii, H., Platinum catalysts for the high-yield oxidation of methane to a methanol derivative. Science 1998, 280, (5363), 560-564.

[27] Cortright, R. D.; Davda, R. R.; Dumesic, J. A., Hydrogen from catalytic reforming of biomass-derived hydrocarbons in liquid water. Nature 2002, 418, (6901), 964-967.

[28] Burch, R.; Breen, J. P.; Meunier, F. C., A review of the selective reduction of NOx, with hydrocarbons under lean-burn conditions with non-zeolitic oxide and platinum group metal catalysts. Applied Catalysis B-Environmental 2002, 39, (4), 283-303.

[29] Miller, J. T.; Schreier, M.; Kropf, A. J.; Regalbuto, J. R., A fundamental study of platinum tetraammine impregnation of silica 2 . The effect of method of preparation, loading, and calcination temperature on (reduced) particle size. Journal of Catalysis 2004, 225, (1), 203-212.

[30] Tao, A. R.; Habas, S.; Yang, P. D., Shape control of colloidal metal nanocrystals. Small 2008, 4, (3), 310-325.

[31] (a) Kessels, W. M. M.; Knoops, H. C. M.; Dielissen, S. A. F.; Mackus, A. J. M.; van de Sanden, M. C. M., Surface reactions during atomic layer deposition of $\mathrm{Pt}$ derived from gas phase infrared spectroscopy. Applied Physics Letters 2009, 95, (1); (b) Aaltonen, T.; Ritala, M.; Sajavaara, T.; Keinonen, J.; Leskela, M., Atomic layer deposition of platinum thin films. Chemistry Of Materials 2003, 15, (9), 1924-1928. 
[32] Christensen, S. T.; Elam, J. W.; Lee, B.; Feng, Z.; Bedzyk, M. J.; Hersam, M. C., Nanoscale Structure and Morphology of Atomic Layer Deposition Platinum on SrTiO3 (001). Chemistry of Materials 2009, 21, (3), 516-521.

[33] Christensen, S. T.; Elam, J. W.; Rabuffetti, F. A.; Ma, Q.; Weigand, S. J.; Lee, B.; Seifert, S.; Stair, P. C.; Poeppelmeier, K. R.; Hersam, M. C.; Bedzyk, M. J., Controlled Growth of Platinum Nanoparticles on Strontium Titanate Nanocubes by Atomic Layer Deposition. Small 2009, 5, (6), 750-757.

[34] Setthapun, W.; Williams, W. D.; Kim, S. M.; Feng, H.; Elam, J. W.; Rabuffetti, F. A.; Poeppelmeier, K. R.; Stair, P. C.; Stach, E. A.; Ribeiro, F. H.; Miller, J. T.; Marshall, C. L., Genesis and Evolution of Surface Species during Pt Atomic Layer Deposition on Oxide Supports Characterized by in Situ XAFS Analysis and Water-Gas Shift Reaction. Journal of Physical Chemistry C 2010, 114, (21), 9758-9771.

[35] Basic Research Needs: Catalysis for Energy. In Report from the U.S. Department of Energy, Basic Energy Science Workshop, 2007.

[36] Christensen, S. T.; Feng, H.; Libera, J. L.; Guo, N.; Miller, J. T.; Stair, P. C.; Elam, J. W., Supported Ru-Pt Bimetallic Nanoparticle Catalysts Prepared by Atomic Layer Deposition. Nano Letters 2010, 10, (8), 3047-3051.

[37] Lei, Y.; Lu, B.; Greeley, J.; Elam, J., 2011, in preparation.

[38] (a) Bartholomew, C. H., Applied Catalysis A: General 2001, 212, 17-60; (b) Sault, A. G., and V. Tikare, Journal of Catalysis 2002, 211, 19-32; (c) Datye, A. K., Q. Xu, K. C. Kharas, and J. M. McCarty, Catalysis Today 2006, 111, 59-67; (d) Bernal, S., J.J. Calvino, C. LoÂpez-Cartes, J.M. Pintado, J.A. PeÂrez-Omil, J.M. Rodrõ̂Aguez-Izquierdo, K. Hayek, and G. Rupprechter, Catalysis Today 1999, 52, 29-43.

[39] (a) Park, J.-N., A. J. Forman, W. Tang, J. Cheng, Y-S. Hu, H. Lin, and E. W. McFarland, Small 2008, 4, (10), 1694-1697; (b) Kanazawa, T., Catalysis Letters 2006, 108, (1-2), 4547; (c) Takenaka, S., H. Matsumori, K. Nakagawa, H. Matsune, E. Tanabe, and M. Kishida, Journal of Physical Cheistry: C 2007, 111, 15133-15136; (d) Zhao, M., L. Sun, and R. M. Crooks, Journal of the American Chemical Society 1998, 120, 4877-4878; (e) Arnal, P. M., M. Comotti, and F. Schuth, Angewandte Chemie-International Edition 2006, 45, 8224-8227; (f) Joo, S. H., J. Y. Park, C-K. Tsung, Y. Yamada, P. Yang and G. A. Somorjai, Nature Materials 2009, 8, 126-131; (g) Ott, L. S., and R. G. Finke, Coordination Chemistry Reviews 2007, 251, 1075-1100; (h) Seipenbusch, M., and A. Binder, Journal of Physical Cheistry: C 2009, 113, 20606-20610.

[40] Feng, H.; Lu, J. L.; Stair, P. C.; Elam, J. W., Alumina Over-coating on Pd Nanoparticle Catalysts by Atomic Layer Deposition: Enhanced Stability and Reactivity. Catalysis Letters 2011, 141, (4), 512-517. 


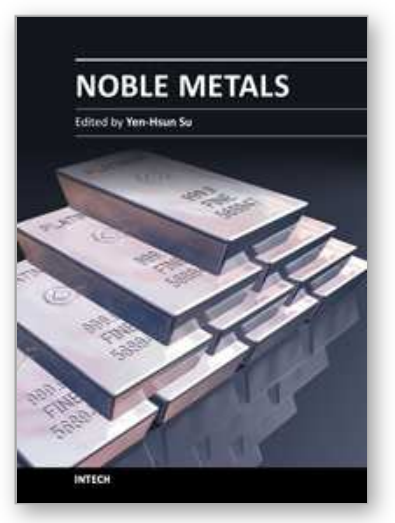

\author{
Noble Metals \\ Edited by Dr. Yen-Hsun Su
}

ISBN 978-953-307-898-4

Hard cover, 426 pages

Publisher InTech

Published online 01, February, 2012

Published in print edition February, 2012

This book provides a broad spectrum of insights into the optical principle, resource, fabrication, nanoscience, and nanotechnology of noble metal. It also looks at the advanced implementation of noble metal in the field of nanoscale materials, catalysts and biosystem. This book is ideal not only for scientific researchers but also as a reference for professionals in material science, engineering, nonascience and plasmonics.

\title{
How to reference
}

In order to correctly reference this scholarly work, feel free to copy and paste the following:

Junling Lu, Yu Lei and Jeffrey W. Elam (2012). Atomic Layer Deposition of Noble Metals - New Developments in Nanostructured Catalysts, Noble Metals, Dr. Yen-Hsun Su (Ed.), ISBN: 978-953-307-898-4, InTech, Available from: http://www.intechopen.com/books/noble-metals/atomic-layer-deposition-of-noble-metals-newdevelopments-in-nanostructured-catalysts

\section{INTECH}

open science | open minds

\author{
InTech Europe \\ University Campus STeP Ri \\ Slavka Krautzeka 83/A \\ 51000 Rijeka, Croatia \\ Phone: +385 (51) 770447 \\ Fax: +385 (51) 686166 \\ www.intechopen.com
}

\author{
InTech China \\ Unit 405, Office Block, Hotel Equatorial Shanghai \\ No.65, Yan An Road (West), Shanghai, 200040, China \\ 中国上海市延安西路65号上海国际贵都大饭店办公楼 405 单元 \\ Phone: +86-21-62489820 \\ Fax: $+86-21-62489821$
}


(C) 2012 The Author(s). Licensee IntechOpen. This is an open access article distributed under the terms of the Creative Commons Attribution 3.0 License, which permits unrestricted use, distribution, and reproduction in any medium, provided the original work is properly cited. 